\title{
Ability to switch reproductive mode in Artemia is related to maternal heterozygosity
}

\author{
Gonzalo M. Gajardo*, John A. Beardmore \\ School of Biological Sciences, University College of Swansea, Swansea SA2 8PP, United Kingdom
}

\begin{abstract}
Brine shrimp Artemia spp. produce young as larvae or as encysted embryos resistant to unfavourable conditions. The factors controlling the switch between the 2 types of reproduction are unknown. Studies on A. tranciscana from the Great Salt Lake of Utah, USA, show the percentage of zygotes produced as cysts is correlated with the level of heterozygosity (determined electrophoretically) in the mother. More heterozygous females also produce more zygotes, and tend to produce more broods and start to reproduce at a younger age than less heterozygous females. Coefficients of variation of reproductive characters are lower for more heterozygous and higher for less heterozygous mothers These results show that heterozygosity in this species is highly correlated with important components of fitness and suggest that the ability to switch reproductive mode, a feature of considerable adaptive value in varying environments, and of importance in aquaculture, has a high degree of genetic determination.
\end{abstract}

\section{INTRODUCTION}

Life history traits are important attributes of organisms often considered synonymous with fitness as they exert a direct influence on expressed reproduction (Istock 1982). Ecological models based on optimality of life history characters predict that individuals with patterns of reproduction and survivorship most suited to maximize fitness in their environment will be favoured by natural selection (Begon \& Mortimer 1986). Consequently, in different sprecies, varying reproductive strategies have evolved as compromise solutions to the problems posed by specific environments and these strategies have a strong impact on the demographic schedules of populations and on the forces acting on gene frequencies.

Some fraction of the existing genetic variation in many species is likely to represent variation with respect to fitness as it affects developmental stability, growth rate and physiological responses of different genotypes (Mitton \& Grant 1984, Zouros \& Foltz 1987). A review of data on correlations between heterozygosity and life history also shows that about $20 \%$ of the variance is explained by association with ecological heterogeneity (Nevo et al. 1984). In order, therefore, to

\footnotetext{
- Present address: Instituto Profesional de Osorno, Osorno, Chile
}

predict the course of evolution for life history traits and to make inferences about the forces of natural selection affecting them, an analysis of the genetic variation underlying these characters in species in particular environments is required. In most of the cases so far examined, however, only individual components of fitness have been analyzed, under the assumption that other components of fitness are correlated with those actually measured. However, composite life history variables such as survival and fecundity are likely to affect fitness in a complex way due to co-variation between them.

This paper addresses the problem of how the genetic variability underlying prime life history traits such as the ability to switch reproductive pattern, fecundity, viability and time to first reproduction is distributed between individuals in a population of Artemia franciscana. Artemia is an Anostracan crustacean with a striking capacity to live in high salinity waters (Sorgeloos 1980). Complex patterns of microspeciation linked to a complex set of ecological circumstances have led to the differentiation of a least 5 bisexual and many parthenogenetic species (Abreu-Grobois \& Beardmore 1980, 1982). A. franciscana, the dominant New World species, is distributed over much of the Western hemisphere, in a series of scattered marine and inland environments. Probably because of this, the species (which as a whole has a gene pool with 
high genetic variability) displays considerable genetic heterogeneity between strains (Beardmore \& AbreuGrobois 1983), which ultimately is likely to lead to differences in life history patterns (Browne et al. 1984). The reproductive strategy of Artemia is to allocate maximum energy to gamete production (Grosch 1980). Mixed strategies are possible, since Artemia is frequently found either as a colonizer or in established populations with high densities of individuals (Browne 1980). In the first case an emphasis on the early and rapid production of a large number of offspring in each brood would seem to be of selective advantage, while in the second the reproductive effort should be proportionally distributed over life span. However, in addition to quantity, the quality or type of zygote is significant for the survival of brine shrimp populations, since 2 reproductive modes, namely encystment and viviparity, exist. All known Artemia strains combine both types with the ratio varying widely among them (Browne 1980). Shunting offspring into a dormant, encysted state is an effective way to assure the survival of the species in unfavourable conditions, since cysts can resist very extreme environmental conditions indeed (Versichele \& Sorgeloos 1980). The factors inducing females to produce cysts have up to now, been believed to be environmental in nature (Browne et al. 1984).

\section{MATERIALS AND METHODS}

Cysts from the Great Salt Lake of Utah, USA (harvested in 1978) were mass hatched in Instant Ocean and after $24 \mathrm{~h}$ transferred into brine $(90 \%$ ). Prior to sexual maturity, the shrimps were removed from mass culture and placed, as randomly taken single pair matings, in individual vials containing $20 \mathrm{ml}$ of brine. On alternative days and just prior to feeding, viviparous offspring were counted and were transferred into separate bottles containing $200 \mathrm{ml}$ of brine, where they were maintained until maturity in order to determine the proportion surviving to adulthood and the sex ratio (no. of females as proportion of total adults). Oviparous offspring (cysts) were filtered and counted. The observation period lasted $45 \mathrm{~d}$, a time sufficient for a major part of the reproductive span to have elapsed.

All observations were conducted at $25^{\circ} \mathrm{C}$ in a constant temperature room. Alga Dunaliella tertiolecta was used as a food.

Six polymorphic enzyme loci (EST-D, 6-PGDH, IDH-1, IDH-2, PGM and PGI) were chosen on the basis of the work of Abreu-Grobois \& Beardmore (1980). The number of heterozygous loci ( 0 to 5 ) was determined for each female. Heterozygosity classes were then assigned as follows: Class $0=0$ loci heterozygous, $1=$
1 locus heterozygous, $2=2$ loci heterozygous, $3+=3$ or more loci (Table 1).

The hypothesis that heterozygosity and components of reproductive performance are not associated was compared with an alternative hypothesis of association by an analysis of variance by ranks (Meddis 1984) using a specific test that there should be a monotomically increasing trend of ranks with increasing heterozygosity. The observation that increasing multilocus heterozygosity appears to be inversely associated with phenotypic variability was also analyzed. In this case a monotomically decreasing trend of ranks with heterozygosity was tested. Ranks 1, 2, 3 and 4 were assigned to reproductive characters in each of the heterozygosity classes 0 to 3 , the class with the lowest value being assigned Rank 1. Variances were expressed as coefficients of variation (CV) and the class with the highest $C V$ was assigned a rank of 4 . Regressions shown for comparisons in Table 2 were calculated as in Sokal \& Rohlf (1981).

\section{RESULTS}

Data on reproductive performance for 4 heterozygosity classes are summarized in Table 1. Although in some cases high standard errors could reflect high levels of intraclass variation (probably due to the low number of females in each heterozygosity class), the data are likely to be reliable as they are based on many broods per female.

A significant positive association of the total number of zygotes (cysts plus larvae) with heterozygosity was found using the ranks test $(p<0.05 ; L=714, Z=1.66$; Table 2). The number of broods per female also shows a positive relationship with heterozygosity though the relationship is not quite statistically significant. Interestingly, while the number of cysts per female increases significantly with heterozygosity $(p<0.05$; $L=759, \quad Z=1.67$ ) the number of live offspring decreases, although the latter relationship is not statistically significant. The fact that the fraction of broods encysted ( $\%$ offspring encysted) is very strongly correlated with heterozygosity $(p<0.01 ; L=743, Z=2.34$ ) indicates that the capacity of a female to produce either cysts or larvae, a phenomenon so far poorly understood, is significantly associated with her degree of heterozygosity

Although the relationships are not statistically significant, heterozygosity is negatively correlated with time to first brood and with days between broods, which may suggest a biological tendency of more heterozygous females towards early reproduction and continued production of offspring over life span. Thus, more heterozygous females (Class $3+$ ) produce their 
Table 1. Artemia franciscana. Reproductive performance $(\overline{\mathrm{x}} \pm \mathrm{SE}$ ) of females from Great Salt Lake in 4 heterozygosity classes. Coefficients of variation are shown in parentheses. The viability of offspring as \% reaching sexual maturity is given in the last line of the table

\begin{tabular}{|c|c|c|c|c|}
\hline \multirow[t]{3}{*}{ Trait } & \multicolumn{4}{|c|}{ Heterozygosity class } \\
\hline & 0 & 1 & 2 & $3^{+}$ \\
\hline & 4 & 6 & 6 & $6^{a}$ \\
\hline Total no. of zygotes & $\begin{array}{c}579.6 \pm 195.5 \\
(58.4)\end{array}$ & $\begin{array}{c}608.0 \pm 140.0 \\
(51.5)\end{array}$ & $\begin{array}{c}703.5 \pm 64.2 \\
(20.4)\end{array}$ & $\begin{array}{c}899.5 \pm 98.0 \\
(26.7)\end{array}$ \\
\hline No. of cysts per female & $\begin{array}{c}60.8 \pm 49.9 \\
(141.9)\end{array}$ & $\begin{array}{c}234.5 \pm 108.0 \\
(103.2)\end{array}$ & $\begin{array}{c}275.8 \pm 79.0 \\
(64.2)\end{array}$ & $\begin{array}{c}527.2 \pm 97.0 \\
(45.1)\end{array}$ \\
\hline No. of nauplii per female & $\begin{array}{c}518.8 \pm 207.8 \\
(69.3)\end{array}$ & $\begin{array}{c}373.5 \pm 46.7 \\
(28.0)\end{array}$ & $\begin{array}{c}427.2 \pm 96.3 \\
(50.4)\end{array}$ & $\begin{array}{c}372.3 \pm 71.9 \\
(43.2)\end{array}$ \\
\hline Fraction $(\%)$ of broods encysted & $\begin{array}{c}13.1 \pm 10.9 \\
(144.7)\end{array}$ & $\begin{array}{c}26.8 \pm 11.3 \\
(94.9)\end{array}$ & $\begin{array}{c}31.0 \pm 8.3 \\
(60.1)\end{array}$ & $\begin{array}{c}52.0 \pm 7.9 \\
(34.0)\end{array}$ \\
\hline Time to 1st brood (days) & $\begin{array}{c}33.8 \pm 9.1 \\
(53.8)\end{array}$ & $\begin{array}{c}27.3 \pm 1.8 \\
(16.2)\end{array}$ & $\begin{array}{c}28.3 \pm 2.3 \\
(19.5)\end{array}$ & $\begin{array}{l}25.0 \pm 0.6 \\
(6.2)\end{array}$ \\
\hline No. of broods per female & $\begin{array}{l}5.8 \pm 2.1 \\
(62.1)\end{array}$ & $\begin{array}{c}7.3 \pm 2.1 \\
(28.8)\end{array}$ & $\begin{array}{l}7.0 \pm 0.8 \\
(27.1)\end{array}$ & $\begin{array}{l}8.5 \pm 0.8 \\
(22.4)\end{array}$ \\
\hline Days between broods & $\begin{array}{l}5.1 \pm 1.2 \\
(33.5)\end{array}$ & $\begin{array}{l}4.5 \pm 0.5 \\
(49.8)\end{array}$ & $\begin{array}{c}4.3 \pm 0.3 \\
(28.9)\end{array}$ & $\begin{array}{l}4.2 \pm 0.4 \\
(27.3)\end{array}$ \\
\hline Live offspring per brood & $\begin{array}{c}106.3 \pm 7.9 \\
(32.5)\end{array}$ & $\begin{array}{c}77.3 \pm 7.0 \\
(47.9)\end{array}$ & $\begin{array}{c}86.0 \pm 7.7 \\
(45.4)\end{array}$ & $\begin{array}{c}98.6 \pm 6.7 \\
(32.2)\end{array}$ \\
\hline Viability & $37.2 \pm 3.8$ & $52.4 \pm 5.0$ & $49.2 \pm 3.6$ & $43.7 \pm 3.0$ \\
\hline
\end{tabular}

Table 2. Artemia franciscana. Analysis of regression of 8 individual reproductive characters on heterozygosity. Values for $A$ ( $y$-intercept) and $b$ (slope) are given for the equation: Reproductive performance $=A+H b$, where $H$ is heterozygosity class. R.C.: reproductive character (see Table 1)

\begin{tabular}{|lrrrr|}
\hline R.C. & $A$ & $b$ & df & $p$ \\
\hline Total zygotes & 527.07 & 110.8 & 20 & $<0.05$ \\
Cysts per ? & 57.78 & 144.4 & 20 & $<0.01$ \\
Nauplii per 9 & 469.30 & -33.6 & 20 & N.S. \\
\% broods encysted & 12.5 & 12.2 & 20 & $<0.01$ \\
Time to 1st brood & 32.0 & -2.3 & 20 & N.S. \\
Broods per Q & 6.0 & 0.8 & 20 & N.S. \\
Days between broods & 4.9 & -0.2 & 135 & N.S. \\
Offspring per brood & 91.4 & -0.6 & 97 & N.S. \\
\hline
\end{tabular}

first broods about $8 \mathrm{~d}$ ( $\overline{\mathrm{x}}: 25.0 \pm 0.63$ ) sooner than less heterozygous females $(\overline{\mathrm{x}}: 33.6 \pm 9.18)$. In the same way, Class $3+$ females would have about 2 more broods ( $\bar{x}: 8.5 \pm 9.76)$ than Class 0 females ( $\bar{x}: 5.8 \pm$ 1.80) over the observation period. Only the characters 'total zygotes', 'number of cysts per female' and 'fraction of broods encysted' are associated with heterozygosity in a statistically significant way. However, accepting that production of cysts diminishes the production of nauplii, all of the other characters except 'live offspring per brood' show superficially the relationship that would be expected from positive effects of heterozygosity upon Darwinian fitness.

It is also noteworthy that in general there is a nega-
Table 3. Artemia franciscana. Rank analysis of the relationship between heterozygosity and coefficient of variation for 8 reproductive characters. Agreement between pattern of coefficients and $C V$ is significant $(p<0.05, L=1470, Z=1.86$ )

\begin{tabular}{|cccc|}
\hline $\begin{array}{l}\text { Het. } \\
\text { class }\end{array}$ & $\begin{array}{c}\text { Rank } \\
\text { sums }\end{array}$ & $\begin{array}{c}\text { Rank } \\
\text { mean }\end{array}$ & $\begin{array}{c}\text { Assigned } \\
\text { coefficient }\end{array}$ \\
\hline 0 & 214 & 26.8 & 4 \\
1 & 142 & 17.8 & 3 \\
2 & 111 & 13.9 & 2 \\
3 & 94 & 11.8 & 1 \\
\hline
\end{tabular}

tive association between heterozygosity class and variance. The consistency of this trend is examined in Table 3 which gives the results for analysis of variance of coefficients of variation for the 8 reproductive characters. Clearly the increase in heterozygosity is significantly associated with decrease in variance.

The Great Salt lake population appears to be genetically programmed to produce many cysts. The cost associated with this strategy is high as the production of a cyst requires more energy than the production of a diocied larva. As can be seen from Fig. 1, the total energy invested in reproduction by a female increases with her heterozygosity. Vanhaecke et al. (1983) have shown that cysts contain 30 to $40 \%$ more energy than freshly hatched nauplii. Of course, much or all of this additional energy has to be expended on the hatching and early developmental processes so that any benefit 


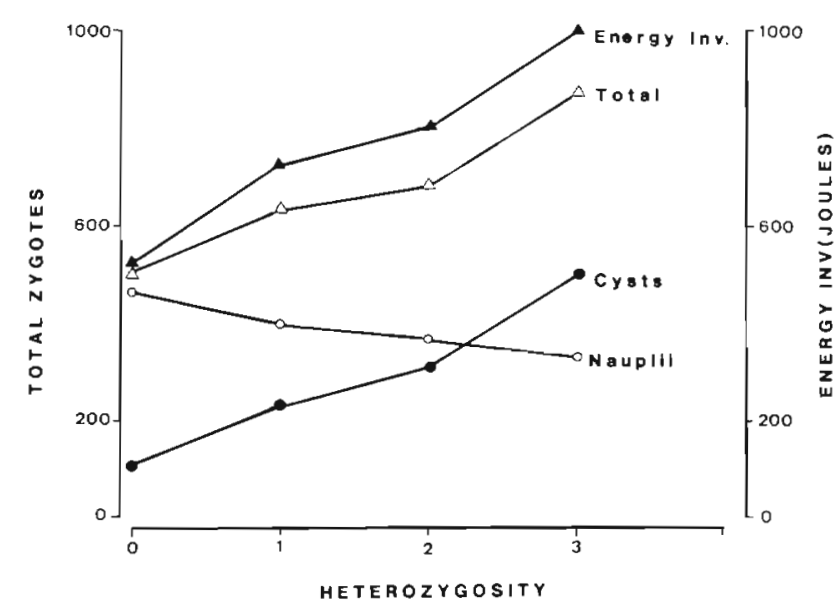

Fig. 1. Artemia franciscana. Reproductive performance (cysts, nauplii and total zygotes) and energy investment for females in 4 heterozygosity classes. Energy investment is the sum of $N+C E$, where $N$ and $C$ represent the amounts of energy (in Joules) allocated to nauplii and cysts, respectively. $E$ is a constant value (1.4) calculated according to data given in vanhaecke et al. (1983)

to the zygote of the additional energy has to be seen strictly within the context of the survival probabilities attached to a cyst. Nevertheless, the female producing a given number of cysts has to allocate significantly more energy to this than to the production of the same number of nauplii. Thus the capacity to produce a larger number of cysts indicates unequivocally an ability to provide the higher energy content required and more heterozygous females are evidently better able to do this.

Live offspring have rather low viability under the experimental conditions used. The percentage of individuals reaching sexual maturity (last line of Table 1) is not correlated with maternal heterozygosity, a not unexpected finding as, unless a maternal influence is operating, viability is expected to be determined by the zygote genotype. Moreover, the more heterozygous females are less likely to produce offspring with heterozygosity levels like their mothers than are less heterozygous females. If larval viability also depends on heterozygosity, females within the middle range of this character should produce those young with the highest viabilities. This appears to be the case as the young with highest viabilities are derived from the intermediate maternal heterozygosity classes 1 and 2 . The sex ratio of live offspring is slightly skewed towards female in all heterozygosity classes (but differences between heterozygosity class means are not significant). This is a common observation in Artemia, especially in conditions of some environmental stress. which may cause greater mortality for males than females (Browne 1982).

\section{DISCUSSION}

The ability of all Artemia females to produce dormant cysts instead of free swimming nauplii is a reproductive device that gives great survival advantage to the species. In opposition to the view that the character is under environmental control (low food availability, low dissolved oxygen or high salinity; Browne 1982) the present results suggest that the ability of $A$. franciscana females to switch reproductive mode is associated, at least in part, with their levels of heterozygosity. Thus, when cyst production is high in any population (as frequently occurs seasonally), it is plausible to suppose that the more heterozygous females may also be more resistant to adversity than less heterozygous ones and are then more able to produce cysts over longer periods.

The data reported here also give support both to theoretical analysis predicting an increase in the fitness of a genotype with the number of heterozygous loci it contains (Turelli \& Ginsburg 1983) and to the fact that increased heterozygosity is often associated with decreased phenotypic variability. This latter phenomenon is of great biological significance (Gillespie 1977) but still awaits satisfactory mechanistic explanations (Chakraborty 1987). On the other hand, the results overall suggest an interesting way to retain genetic variability. In fact, as the more heterozygous females play a key role of helping to assure the continuity of the population in time through cyst production, their potential to maximize the rate of evolutionary change is great, especially in conditions when drastic reduction in population size might, otherwise, lead to reduced genetic variability (bottle-neck effect). Retention of genetic variability under stress conditions is a significant factor, whose evolutionary significance is currently of great interest (Parsons 1987). The strategy displayed by Artemia franciscana in the Great Salt lake is a compromise allocation of energy to the production of cysts in response to an unstable environment. The Great Salt lake is a thalassohaline ( $\mathrm{NaCl}$-rich water) habitat located inland. It suffers considerable seasonal changes in temperature. Nauplii appear in early spring (D'Agostino 1980 ), when the temperature is about 15 to $25^{\circ} \mathrm{C}$. Their maximum abundance occurs through the summer, but they are no longer found in December, when the lake is frozen. Under this seasonal adversity live individuals are eliminated by freezing temperatures and the Artemia population from the Great Salt lake becomes seasonally dormant. The benefits associated with dormancy in this case are simply the increased chance of establishment and reproduction after the environment has improved. The main cost associated with this strategy is that of diverting energy away from active reproduction towards the maintenance of a welladapted dormant stage which is more expensive than 
viviparous reproduction (Vanhaecke et al. 1983). Recognising that extra energy is required to maintain high osmoregulatory efficiency in conditions of high salinity (normally associated with cyst production) the greater reproductive success achieved by multiply heterozygous individuals may be postulated to be due to their better utilization of energy. Thus, under similar experimental conditions, the more heterozygous females are able to allocate more energy to produce offspring as cysts than are less heterozygous females. A similar explanation has been given to explain heterozygote advantage in lowering the rate of oxygen consumption in the oyster Crassostrea virginica (Koehn \& Shumway 1982).

In summary, our results provide experimental evidence in support of the genetic control of the highly adaptive reproductive strategy of switching the quality of the offspring, in a heterogeneous environment, displayed by female Artemia in the Great Salt Lake. Although this strategy involves some energetic cost, the benefits (survival of the population) outweigh the costs. The behaviour of the whole set of life history traits analyzed in this population is best explained as being evolved as a response to a seasonal environment. These results are likely to be extrapolable both to many Artemia strains and to many invertebrate species inhabiting stressful and variable environments. They are also of significance for the production of cysts in aquaculture.

Acknowledgements. We are indebted to Drs R. Brown, P. Sorgeloos and D. O. F. Skibinski for advice. Cysts were kindly provided by the Artemia Reference Center, Belgium. Research was supported by the British Council, whose help is gratefully acknowledged.

\section{LITERATURE CITED}

Abreu-Grobois, F. A., Beardmore, J. A. (1980). International study on Artemia. II. Genetic characterization of Artemia populations - an electrophoretic approach. In: Persoone, G., Sorgeloos, P., Roels, O., Jaspers, E. (eds.) The brine shrimp Artemia, Vol I, Morphology, genetics, radiobiology, toxicology. Universa Press, Wetteren, p. 133-146

Abreu-Grobois, F. A., Beardmore, J. A. (1982). Genetic differentiation and speciation in the brine shrimp Artemia. In: Barigozzi, C. (ed.) Mechanisms of speciation. Alan R. Liss, Inc., New York, p. 345-376

D'Agostino, A. (1980). The vital requirements of Artemia, physiology and nutrition. In: Persoone, G., Sorgeloos, P., Roels, O., Jaspers, E. (eds.) The brine shrimp Artemia, Vol 2, Physiology, biochemistry, molecular biology. Universa Press, Wetteren, p. 55-82

Beardmore, J. A., Abreu-Grobois, F. A. (1983). Taxonomy and evolution in the brine shrimp Artemia. In: Oxford, G. S., Rollinson, D. (eds.) Protein polymorphism: adaptive and taxonomic significance. Academic Press, London, p. $153-164$

This article was submitted to the editor
Begon, M., Mortimer, M. (1986). Population ecology. A unified study of animals and plants, 2nd edn. Blackwell Scientific Publications, London

Browne, R. A. (1980). Reproductive pattern and mode in the brine shrimp. Ecology 61, 466-470

Browne, R. A. (1982). The costs of reproduction in brine shrimp. Ecology, 63: 43-47

Browne, R. A., Salle, S. E., Grosch, D. S., Sagrati, V. O., Purser, S. M. (1984). Partitioning genetic and environmental components of reproduction and lifespan in Artemia. Ecology 65: 949-960

Chakraborty, R. (1987). Biochemical heterozygosity and phenotypic variability of polygenic traits. Heredity 39: 19-28

Gillespie, J. H. (1977). Natural selection for variances in offspring numbers: a new evolutionary principle. Am. Nat. 111: 1010-1014

Grosch, D. S. (1980). Alterations to the reproductive performance of Artemia caused by antifouling paints, algaecides, and aquatic herbicides. In: Persoone, G., Sorgeloos, P., Roels, O. A., Jaspers, E. (eds.) The brine shrimp Artemia, Vol 1 Morphology, genetics, radiobiology, toxicology. Universa Press, Wetteren, p. 201-211

Istock, C. A. (1982). Some theoretical considerations concerning life history evolution. In: Dingle, H., Hagmann, J. P. (eds.) Evolution and genetics of life history. Springer Verlag, New York, p. 7-20

Koehn, R. K., Shumway, S. E. (1982). A genetic/physiological explanation for differential growth rate among individuals of the oyster Crassostrea virginica (Omelin). Mar. Biol. Lett. 3: 35-42

Meddis, R. (1984). Statistics using ranks. A unified approach. Basil Blackwell Inc., Oxford

Mitton, J. B., Grant, M. C. (1984). Associations among protein heterozygosity, growth rate, and developmental homeostasis. Ann. Rev. Ecol. Syst. 15: 479-499

Nevo, E., Beiles, A., Ben-Shlomo, R. (1984). The evolutionary significance of genetic diversity: ecological, demographic and life history correlates. In: Mani, G. E. (ed.) Evolutionary dynamics of genetic diversity. Springer Verlag, Berlin, p. $12-213$

Parsons, P. A. (1987). Evolutionary rates under environmental stress. In: Hecht, M. K., Wallace, B., Prance, G. T. (eds.) Evolutionary biology, Vol 21 Plenum Press, New York, p. 311-346

Sokal, R. R., Rohlf, F. J. (1981). Biometry. W. H. Freeman and Co., San Francisco

Sorgeloos, P. (1980). Life history of the brine shrimp Artemia. In: Persoone, G., Sorgeloos, P., Roels, O., Jaspers, E. (eds.) The brine shrimp Artemia, Vol I. Universa Press, Wetteren, p. $19-23$

Turelli, M., Ginzburg, L. R. (1983). Should individual fitness increase with heterozygosity? Genetics 104: 191-209

Vanhaecke, P., Lavens, P., Sorgeloos, P. (1983). International Study on Artemia. XVII. Energy consumption in cysts and early larval stages of various geographical strains of Artemia. Annls Soc. r. zool. malacol. Belg. T. 114, fasc. 2: $155-164$

Versichele, D., Sorgeloos, P. (1980). Controlled production of Artemia cysts in batch cultures. In: Persoone, G., Sorgeloos, P., Roels, O., Jaspers, E. (eds.) The brine shrimp Artemia, Vol 3, Ecology, culturing. Use in aquaculture. Universa Press, Wetteren, p. 231-246

Zouros, E., Foltz, D. W. (1987). The use of allelic isozyme variation for the study of heterosis. Isozymes 13: 1-59

Manuscript first received: July 27, 1988

Revised version accepted: April 25, 1989 